\title{
IMPLEMENTATION OF CONCURRENT NURSING AUDIT: AN EXPERIENCE REPORT
}

\author{
Carla Denise Viana ${ }^{1}$ Luciane Zambarda Todendi de Bragas², Daniele Delacanal Lazzari³, Cledir Tania França \\ Garcia ${ }^{4}$, Gisela Maria Schebella Souto de Moura ${ }^{5}$
}

${ }^{1}$ Master's student, Graduate Nursing Program at Universidade Federal do Rio Grande do Sul (UFRGS). CAPES grantee. Porto Alegre, Rio Grande do Sul, Brazil. E-mail: vianaca@ibest.com.br

${ }^{2}$ RN, Internal Audit Service Coordinator, Hospital de Caridade de Ijuí. Ijuí, Rio Grande do Sul, Brazil. E-mail: Itodendi@hci.org.br

${ }^{3}$ Doctoral Student, Graduate Nursing Program at Universidade Federal de Santa Catarina. CNPq grantee. Florianópolis, Santa Catarina, Brazil. E-mail: danielelazza@gmail.com

${ }^{4}$ M.Sc. in University Teaching. RN, Continuing Education Supervisor, Hospital de Caridade de Ijuí. Ijuí, Rio Grande do Sul, Brazil. E-mail: ctfranca@hci.org.br

${ }^{5}$ Ph.D. in Administration, Professor, School of Nursing and Graduate Nursing Program at UFRGS. Porto Alegre, Rio Grande do Sul, Brazil. E-mail: gmoura@hcpa.ufrgs.br

\begin{abstract}
Nursing audit is a management tool capable of assisting in the improvement of care quality and efficiency of hospital charges and may be performed concurrently, in other words, while the patient receives care. This study aims to describe nurses' experience about the implementation of concurrent nursing audit in a hospital environment. This is a report on an experience in the period from 2009 to 2014 at a hospital in the state of Rio Grande do Sul, Brazil. The following steps of this process are discussed: Instrument elaboration, Sensitization of the nursing team and Operation of concurrent audit. The results show the feasibility and benefits of adopting this model, especially regarding the reduction of time to send the bill to the health insurances, greater interaction between auditors and care teams, creation of indicators, and contributions to the improvement of healthcare quality and nursing records.
\end{abstract}

DESCRIPTORS: Nursing audit. Nursing records. Quality of health care. Nurse's role.

\section{IMPLANTAÇÃO DA AUDITORIA CONCORRENTE DE ENFERMAGEM: UM RELATO DE EXPERIÊNCIA}

RESUMO: A auditoria de enfermagem é uma ferramenta de gestão capaz de auxiliar na melhoria da qualidade da assistência e na eficiência das cobranças hospitalares, podendo ser realizada de maneira concorrente, ou seja, enquanto o paciente recebe o atendimento. $\mathrm{O}$ presente estudo tem como objetivo descrever a experiência de enfermeiras acerca da implantação da auditoria concorrente de enfermagem em ambiente hospitalar. Trata-se de um relato de experiência vivenciada no período de 2009 a 2014 em hospital do interior do Rio Grande do Sul, abordando as etapas deste processo: Elaboração do instrumento, Sensibilização da equipe de enfermagem e Operacionalização da auditoria concorrente. Os resultados apontam a viabilidade de se adotar este modelo e benefícios, principalmente no que tange a diminuição do tempo para envio da fatura aos convênios médicos, maior interação entre as auditoras e equipes assistenciais, criação de indicadores, e contribuições para a melhoria da qualidade assistencial e registros de enfermagem.

DESCRITORES: Auditoria de enfermagem. Registros de enfermagem. Qualidade da assistência à saúde. Papel do profissional de enfermagem.

\section{IMPLEMENTACIÓN DE AUDITORIA CONCURRENTE DE ENFERMERÍA: UN RELATO DE EXPERIENCIA}

RESUMEN: La auditoría de enfermería es una herramienta de gestión que puede ayudar a mejorar la calidad del cuidado y eficiencia del los gastos del hospital y se puede realizar de manera concurrente, es decir, mientras el paciente recibe cuidado. Este estudio tiene como objetivo describir la experiencia de las enfermeras sobre la implementación de la auditoría concurrente en el ámbito hospitalario. Es un relato de experiencia vivida en el periodo 2009 a 2014 en un hospital del Río Grande del Sur, Brazil, abordando las fases del proceso: Elaboración del instrumento, Sensibilización del equipo de enfermería y Operacionalización de auditoria concurrente. Los resultados demuestran la viabilidad de adoptar este modelo y sus beneficios, especialmente en relación con la reducción del tiempo para enviar lafactura a los covenants médicos, mayor interacción entre los auditores y equipos de atención, creación de indicadores, y contribuciones para mejorar la calidade de la atención y de los registros de enfermería.

.DESCRIPTORES: Auditoria de enfermería. Registros de enfermería. Calidad de la atención de salud. Rol de la enfermera. 


\section{INTRODUCTION}

Nursing has increasingly conquered space in nursing management. This activity can verify the qualify of nursing care for patients, contributing to its constant improvement. ${ }^{1}$ In addition, it is used to assess the work processes and analyze the hospital accounts.

Due to the requirements of the institutions and the current health scenario, nurse auditors end up focusing their work more on financial issues than on care quality. ${ }^{2}$ Nevertheless, even in this condition, they contribute to the nursing team, client and institution, as they participate in the search to maintain the organizations' financial equilibrium, which permits the continuity of care delivery.

The function of nurse auditor is expanding in the job market, mainly regarding the analysis of the hospital accounts, which consists in verifying the compatibility between what was consumed, what is being charged and the procedures actually performed. ${ }^{3}$

The nursing audit's main means of investigation are the professionals' records in the patient history. Through these records, one can assess the quality of care delivery, determine the precision of the documents, their completeness and identify lost revenues deriving from the hospital bill. ${ }^{4}$

One of the problems faced in the nursing audit is the non-conformity or absence of nursing notes in the history, which cause discrepancies in the hospital charges, indicate errors in the care processes and infringe on ethical and legal aspects of the category. The auditors are responsible for advising the professionals on the need to maintain appropriate records. ${ }^{1}$

The role of the nurse auditors in hospitals departs from the premise that the nursing team activities need to be assessed in search of evidences on the delivery of high-quality care and charges to health insurance operators. The auditors need to play an educative and impartial role in the development of their function. ${ }^{5}$

The great space the audit focused on the hospital accounts has conquered sees its future threatened. The increasing presence of quality management programs in hospitals projects that a change will occur in the conception of nursing audit, which will move from the solely financial view to a configuration focused on care quality. ${ }^{2}$

In that sense, an audit process needs to be elaborated that can link care quality and hospital changes with the daily reality of nurse auditors. The literature demonstrates that there exist three audit modalities: retrospective, concurrent and prospective. The retrospective takes place after the patient's discharge; the concurrent while the patient receives care; and the prospective refers to the audit done before care. ${ }^{6}$

Putting in practice the concurrent audit in hospitals allows the auditor to be in loco at the patient's care service and in contact with the nursing team, witnessing divergences in the notes, solving the professionals' doubts and visiting the patient when necessary. Nevertheless, most institutions work with the retrospective modality ${ }^{2}$ and, consequently, the literature about concurrent audit is scarce, making to difficult to support the practice.

In that sense, the objective in this report is to describe the experience of nurses in the implementation of the concurrent nursing audit at a hospital in the state of Rio Grande do Sul. Thus, the intent is to contribute to the nursing audit in terms of its functionality in the hospital context.

\section{METHOD}

This is an experience report on the implementation of the concurrent nursing audit at a general hospital in a Northwestern city of the state of Rio Grande do Sul, between 2009 and 2014. In compliance with ethical requirements, consent was obtained from the organization for this description.

\section{The context of the study field}

The study hospital is a macro-regional highcomplexity institution, attending to 70 to $80 \%$ of patients through the Unified Health System (SUS), and the other patients through health insurances or private care. Its structure consists of 220 hospital beds, distributed in eight inpatient wards, three intensive care wards and an emergency care service. In addition, the hospital offers outpatient services in different specialties and a surgical center.

In 2007, the hospital organization implemented a computer system that addressed some items from the patient history, such as the medical prescription and the nursing prescription, both of which are electronic. Nevertheless, most nursing records were still done manually, by completing standardized forms that contained items like: vital signs, nursing evolution, manual medication checking, besides manual notes of the nursing procedures applied to the patient.

At the same time as the implementation of the computer system, the hospital created an inventory 
control at the care services, which is in use until date. This consists in the maximum number of materials available at the wards and which are replaced weekly by the internal pharmacy, in response to the use with the patients the nursing professionals have typed.

For each patient, every day, an expense form is used, which is valid for the same period as the medical and nursing prescription, i.e. 24 hours. This form is divided in three shifts: morning, afternoon and night. When the professionals deliver care and use material from the inventory, they register this on the expense form and then type it in the computer system. The internal pharmacy, in turn, monitors the need for replacement per product and service. When the employee does not register the information, registers it inappropriately or does not type it, an error happens in the provision of the service.

The creation of the inventory control at the wards and the implementation of the computer system strengthened the importance of the nursing records in the patient histories. In this institutional context, in 2009, the practice of the nursing audit had to be reconsidered, expanding its role.

\section{Short history on the audit at the institution}

In 2002, the institution implemented the Internal Audit Committee (COMAI), consisting of one physician and two nurses, who worked with the analysis of the records after the execution through the retrospective audit of the patient histories. The nurse auditors received the patient histories and the consumption reports and then analyzed the care, checking the compatibility between the materials, medication, taxes, medicinal gases, daily fees in isolation and the records of the procedures performed. Then, the report was forwarded to the billing sector, which made the adaptations indicated and sent the hospital bill to the health insurance.

The auditors' contact with the other nursing professionals at the hospital was restricted and resulted from divergences found in the use of inputs that were not appropriate for the care delivered and from training about the records. Some problems faced in this period referred to the long time between the patient's discharge and the sending of the hospital bill to the health insurance and the shortcoming in the patient file.

Through the search to improve the services and the concern with the quality of care delivery to the patient, auditing was acknowledged as a tool capable of providing quality indicators. In this perspective, the nursing audit at the institution was evolving from a mere supervisory role of the records and the presentation of the hospital bill to a focus on the quality of care, in the attempt to combine the hospital charges with the quality of care delivery.

Then, the choice was made to change the way the audit was done, from the retrospective model to the concurrent one. The project was based on in loco audits at the wards and real time contact with the nursing professionals in care practice, solving doubts about the records, disagreements on the entries of material consumed and measuring the shortcomings in the nursing records.

Based on this line of thought and strongly believing in the new proposal, in 2009, the auditors proposed the implementation of concurrent audit through a pilot plan, to be applied at two inpatient wards. The project consisted of three main steps, called Elaboration of the tool, Sensitization of the nursing team and Operation of concurrent auditing.

\section{Elaboration of the tool}

The first step consisted in the elaboration of an audit tool capable of joining care quality and hospital charge questions, called the Audit Checklist, created for this purpose. This is a print document that serves as a guide for the audit to assess the fundamental data from the nursing notes in the patient file.

This tool was constructed based on meetings among the nurse auditors, nursing management and invoicing professional. Three meetings were held until the final version of the document was obtained. In the first, the auditors presented the preliminary version of a model for the other professionals to cooperate with suggestions and it was determined that that the tool would be tested for two weeks and then reassessed.

To undertake the pilot test, one of the nurse auditors used the tool to assess the history of five patients, daily, for 14 days. In total, 70 checklists were elaborated to establish an efficient test. The result of this test was the removal or addition of items from the tool.

The professionals involved in the structuring of the checklist sought the literature for examples that could serve to support the construction; at that time, however, they were not successful. Then, they used books about health audits, legal resolutions on nursing histories and notes, institutional regulations and requirements from health insurances and the Unified Health System. 
In the elaboration of the final model, the stakeholders' professional experience was combined with theoretical foundations and the practical implementation at the services. This version was structured on a sheet of paper and consisted of the identification, date, signature and description of each item for analysis in the history, including: verification of medication, start and end of the use of medicinal gases and equipment, nursing prescription, verification of tube diets, signature and stamp of the professional, completeness, clarity and erasures in the notes. In addition, blank space was available for additional information by the auditor.

The planning was centered on the daily completion of the checklist and forwarding to the nurse for information and the necessary verifications. The use of this tool was intended to provide quantitative information on the shortcomings in the nursing registers, turning into a quality indicator the nurses could use to monitor the performance of their teams monthly. The strategy also served to support improvements in the nursing records and care quality.

\section{Sensitization of the nursing team}

Once the tool was ready, the nurses and nursing technicians from the care sectors where the project would be applied received explanations. The goal was to share the change in the way the nursing audit was done, to present the idea of the monthly indicator and of the visits to the wards. This moment also served to underline the importance of the nursing records, not only based on hospital charges, but also on ethical, legal and care quality issues.

The professionals' openness during the meeting showed their interest in participating in the process, although some mentioned that they would like to better understand the nursing records and considered the need for more intensive training, besides mentioning difficulties related to the lack of time to elaborate the notes and problems in the computer system of the institution, such as slowness. With these contributions at hand, some measures were taken, such as the inclusion of training on the records as early as the employee was hired.

\section{Operation of concurrent audit}

In the third phase, the concurrent audit was put in practice, with the consent of the Nursing Management and the Invoicing Coordination. It was defined that, every day, the nurse auditor would visit the inpatient wards, analyzing the nursing records, together with the consumption reports.
Doubts were solved at the ward directly with the professionals involved. In addition, one invoicing professional would monitor the audits and make the changes indicated, speeding up the invoicing process of the hospital account.

Three nurse auditors composed the audit committee. These were divided between the two care sectors chosen, with a view to optimizing the work. The units that were part of the pilot project were exclusively focused on care delivery to patients attended through health insurances and privately, and were characterized by a considerable occupancy rate of 80 to $90 \%$. These services were chosen, inferring that the charges for the health insurances are more detailed when compared to the SUS, which reimburses through preset amounts. Thus, besides assessing the care quality, the nurse promoted speedy invoicing.

Two auditors held the audits every afternoon, from Monday to Friday, analyzing the histories and consumption reports and visiting the patient if necessary. In this process, some adaptations were needed, due to launching errors, incoherencies between care and what was actually executed. The auditor indicated these adaptations in the consumption report and adapted in the system by the invoicing professional, who also added items like fees and tests to the hospital account. On average, 25 histories or one day of hospitalization were audited per day, except on Mondays, which totaled three days due to the weekends.

The third nurse auditor applied the checklist at the wards during the morning shift. The intention was to solve shortcomings, if there were any, until the afternoon when the professionals audited the hospital accounts. The checklist was applied to all files, delivered to the ward nurse to be informed of the shortcomings and to find the solution. The checklist was stored in a specific fold at the ward, which was collected in the afternoon to measure the monthly indicators.

The contact between the nurse auditors and the nursing team at the ward was constant, each time there were doubts related to the history and to the care practice they talked and provided further clarifications. The training started to be offered during the work shift and at the ward, allowing everyone to participate.

During the dialogues, technical issues emerged that had to be addressed, like the medication dilution for example. In view of incoherencies between the prescribed drug, what was checked and the items consumed, it could be verified that, some- 
times, the dilutions were not being done as the hospital standards recommended, which could cause errors in patient care. As a result of this diagnosis, the training was intensified and the work processes reconsidered.

Based on the results of the pilot project, the adaptations needed could be made before new sectors were included. The need to insert other items was perceived, such as the assessment of wounds and the dressing changes, adapting the audit tool according to the specialty of the ward where the visits were made. The in loco training was also intensified based on the shortcomings in the nursing notes.

In this first phase, the main difficulties in the execution of the project were based on the auditors' work demand due to the large number of histories, the discrepancies in the hospital accounts due to errors in the nursing records and errors in the entry system of the pharmacy. These barriers were gradually overcome over time, by hiring an additional nurse auditor and by the intense work at the origin of the shortcomings found, aiming for preventive actions in the work teams.

\section{RESULTS}

In 2010, as planned, the concurrent audit was expanded to the other inpatient wards, the adult intensive care ward, the neonatal ward and the cardiac care ward and, in 2011, to the outpatient services and emergency sector. Today, 16 care sectors of the hospital receive the nurse auditors' visit daily, who perform their work in loco. This represents a coverage rate of $72 \%$, considering that, in all sectors where patients are attended in the inpatient modality, the audit takes place and the discoveries refer to specialty outpatient clinics.

On average, 768 checklists are applied monthly, complying with the sampling routine of two files/day per sector, totaling 48 checklists per month for each unit, independently of the health insurance. Based on the daily completion of the tool, the audit indicator can be measured and forwarded to the coordinators from each sector to assess the management performance. Until date, approximately 840 audit reports were made available, which contain the data about shortcomings in the nursing notes, also related to the work shifts.

Besides the checklist, the audits analyze the hospital accounts at the sectors of the institution where the patient is hospitalized or receives outpatient care through a health insurance or privately, aiming to solve the shortcomings in due time for the invoicing and forwarding to the health insurance. On average, 880 accounts are audited per month of health insurances and private accounts including inpatients and outpatients, totaling $100 \%$ of coverage.

Since the modification in the way the audit is done until date, a reduction is perceived in the number of errors in the nursing notes made in the patient files and a reduction in the interval between the discharge and the forwarding of the invoice to the health insurance. The reports provide guidance for the team training. The auditing produces the indicators monthly, which are monitored by the hospital's nursing and financial management.

The impact of the change in the way the audit is put in practice also influence the approximation between the nurse auditors and the nursing professionals directly active in care. A better understanding was perceived about the function of the nurse auditor as an educator and collaborator of service management.

\section{DISCUSSION}

The nurse auditors' practice is part of an educative process and, although the knowledge on this activity can still be considered recent, it can significantly contribute to the profession by creating circumstances for the management of high-quality nursing care. ${ }^{7}$ The audit function should go beyond purely financial issues, verifying exactly the quality of care delivery to the users. Thus, the records in the histories serve as fundamental elements for these assessments, and equally support the communication among the health professionals.

The elaboration of tools to monitor the quality of the nursing notes is a highly valid strategy, provided that these tools are efficient in terms of time and are in accordance with the reality. In Australia for example, the Nursing and Midwifery Content Audit Tool (NMCAT) is used, which supports the nurses' management regarding the monitoring of the nursing documentation. ${ }^{8}$

The use of a checklist is also indicated to audit the patient histories in any health context. It should address all items that are considered important for the assessment, covering the legal and ethical spheres, financial reimbursements and care quality. When well elaborated, the checklist makes it easy to perform the audit. ${ }^{4}$ In that sense, few studies have tried to elaborate audit tools in Brazil, which is why the auditors have organized their own tools.

Most of the nursing professionals are unfamiliar with the activities of the nurse auditors. Studies 
show that the nurse audit is basically related to the hospital costs, verification and control of the medical history. ${ }^{5}$ While the nursing team knows the auditor's functions, however, they see it as a source of educative influences and improvements in the quality of care delivery to the patient. ${ }^{9}$ In view of these points, the sensitization of the nursing professionals is fundamental with a view to a reformulation in the way the audit is done.

Another aspect that should be observed the sustainability of the health institutions, which need to develop economically through efficient management of their countless processes. In Brazil, there are still few scientific studies on the costs of nursing care, although the team's activities in hospital cost control contribute to the efficiency of the institutions. Lack of knowledge on the relation between the cost of therapeutic procedures and the productivity of the services favors waste and makes it difficult for countless possibilities to improve nursing management to emerge. ${ }^{10}$

In that sense, the implementation of the audit can contribute and endorse quality parameters. It can be perceived as a way to systematically assess the nursing care, not only through the records in the patient files, but also through the daily observation of practice and support to the team's actions. The assessment of the efficacy and economy of the health actions uses the audit as an effective management tool and this, in turn, can contribute to the complex planning of health services. In the hospital audits, the incompleteness of the records is frequently detected, a concerning situation, as the payment of procedures, materials, medication are linked to the nursing notes. ${ }^{11}$

The errors in the nursing notes suggest ineffective communication among the professionals, which can harm the patients in the development of the treatment. ${ }^{12}$ Thus, the implementation of the audit can equip the nursing team and strengthen the importance of the nurse auditor in this process through actions and orientations, besides the elaboration of tools for care planning. ${ }^{13}$

\section{CONCLUSION}

In the development of their actions, the nurse auditors should seek nursing care quality as the main objective, without disregarding the hospital cost and charge issues traditionally addressed. The process needs to be elaborated and conducted to respond to all questions that permeate the audit function.
When adopting critical and reflexive thinking, new forms of thinking about the nurse audit in the hospital context can be implemented, assuming the role of daily educator at the services, interacting with the professionals and training them for the necessary improvements identified based on the assessment of the procedures.

The nurse auditors are responsible for positioning themselves in view of the institutions' great current demand, which overvalue the professionals because they add financial values to the hospital accounts to the detriment of the care quality assessment. It should be considered that high-quality care reduces the length of the hospital stay, satisfies the patient and, consequently, provides a favorable "costbenefit" relation to the hospital. It is fundamental for all efforts to be concentrated in this perspective.

In addition, the nurse audit should not center on the function strictly related to the daily patient history analyses. It should look at the patient, the care and the way it is being accomplished. For this operation to be satisfactory, there is nothing better than to include the auditor in the care sectors, observing and assessing the development of the activities.

From this perspective, the implementation of the concurrent nursing audit demonstrates the relevance of this work method applied to the hospital context. The nurses' work in loco tightens the relations with the other professionals. In addition, it helps for the professionals to see the audit not as supervision, but as advice and education for good nursing practices. Another important consideration refers to the auditors' motivation by expanding the range of their activities, through the interaction with the teams, leaving behind the task-based and exhaustive model of reviewing the hospital accounts.

Finally, it can be affirmed that the experience with the evolution from the retrospective to the concurrent audit model was positive, as the benefits of the adoption of the new proposal in comparison with the previous one could be perceived. This report, however, appoints the need to improve this process even further, including it in the perspective of evidence-based practice, that is, in the possibility to assess this experience using a scientific research method. That is undoubtedly the next challenge lying ahead.

\section{REFERENCES}

1. Setz VG, D'Innocenzo M. Avaliação da qualidade dos registros de enfermagem no prontuário por meio da auditoria. Acta Paul Enferm. 2009; 22(3):313-7. 
2. Scarparo AF, Ferraz CA, Chaves LDP, Gabriel CS. Tendências da função do enfermeiro auditor no mercado em saúde. Texto Contexto Enferm. 2010; 19(1):85-92.

3. Silva MVS, Silva LMS, Dourado HHM, Nascimento AAM, Moreira TMM. Limites e possibilidades da auditoria em enfermagem e seus aspectos teóricos e práticos. Rev Bras Enferm. 2012; 65(3):535-8.

4. Hess CT. Audit checklist for medical necessity of provided services. Adv Skin Wound Care. 2010; 23(7):336.

5. Passos MLL, Borges CT, Cavalcante MBPT, Gurgel MGI, Costa MS, Alves MDS. Auditoria de enfermagem: conhecimento de profissionais em hospital público de referência. Rev RENE. 2012; 13(5):1025-33.

6. Motta ALC. Auditoria de enfermagem nos hospitais e operadoras de planos de saúde. $6^{\text {a }}$ edição. São Paulo (SP): Editora Iátria; 2013.

7. Pinto KA, Melo CMM. A prática da enfermeira em auditoria em saúde. Rev Esc Enferm USP. 2010; 44(3):671-8.
8. Johnson M, Jefferies D, Langdon R. The Nursing and Midwifery Content Audit Tool (NMCAT): a short nursing documentation audit tool. Nurs Manag. 2010; 18(7):832-45.

9. Pereira PM, Porto AR, Thofehrn MB. A importância do enfermeiro auditor na qualificação da assistência profissional. Rev Enferm UFPE On Line. 2010; 4(2):504-9.

10. Albano TC, Freitas JB. Participação efetiva do enfermeiro no planejamento: foco nos custos. Rev Bras Enferm. 2013; 66(3):372-7.

11. Silva JA, Grossi ACM, Haddad MCL, Marcon SS. Avaliação da qualidade das anotações de enfermagem em unidade semi-intensiva. Esc Anna Nery. 2012; 16(3):576-81.

12. Gartlan J, Smith A, Clennett S, Walshe D, TomlinsonSmith A, Boas L, et al. An audit of the adequacy of acute wound care documentation of surgical inpatients. J Clin Nurs. 2010; 19(15-16):2207-14.

13. Menezes JGBRL, Bucchi SM. Auditoria em enfermagem: um instrumento para assistência de qualidade. Rev Enferm UNISA. 2011; 12(1):68-72. 